11. NINOS Study Group. Inhaled nitric oxide in term and near-term infants: neurodevelopmental follow-up of the Neonatal Inhaled Nitric Oxide study group (NINOS). $J$ Pediatr 2000;136:611-17.

12. Golding J, Pembrey M, Jones R, et al. ALSPAC - the Avon Longitudinal Study of Parents and Children I. Study methodology. Pediatr Perinat Epidemiol 2001;15:74-87.

13. Lawlor DA, Cooper AR, Bain C, et al. Association of birth size and duration of breast feeding with cardiorespiratory fitness in childhood: findings from the Avon Longitudinal Study of Parents and Children (ALSPAC). Eur J Epidemiol 2008;23:411-22.

14. Kotecha SJ, Watkins WJ, Heron J, et al. Spirometric lung function in school-age children. Effect of intrauterine growth retardation and catch-up growth. Am J Respir Crit Care Med 2010;181:969-74.

15. Chinn S, Rona RJ. Height and age adjustment for cross sectional studies of lung function in children aged 6-11 years. Thorax 1992;47:707-14.

16. Munkata M, Ohe M, Homma Y, et al. Pulmonary dysanapsis, methacholine airway responsiveness and sensitization to airborne antigen. Respirology 1996;2:113-18

17. Yan K, Salcome C, Woolcock AJ. Rapid method for measurement of bronchial responsiveness. Thorax 1983:38:760-5.

18. Melamed N, Klinger G, Tenenbaum-Gavish K, et al. Short-term neonatal outcome in low-risk, spontaneous, singleton, late preterm deliveries. Obstet Gynecol 2009:14:253-60.

19. Boyce TG, Mellen BG, Mitchel EF Jr, et al. Rates of hospitalization for respiratory syncytial virus infection among children in Medicaid. J Pediat 2000;137:860-70
20. Gouyon JB, Vintejoux A, Sagot P, et al. Neonatal outcome associated with singleton birth at 34-41 weeks of gestation. Int J Epidemiol 2010;39:769-76.

21. Jobe AJ. The new BPD: an arrest of lung development. Pediatr Res 1999:46:641-3.

22. Maxwell NC, Davies PL, Kotecha S. Antenatal infection and inflammation: what's new? Curr Opin Infect Dis 2006:19:253-8.

23. Thomas W, Speer CP. Chorioamnionitis: important risk factor or innocent bystande for neonatal outcome? Neonatology 2011;99:177-87.

24. Watterberg KL, Demers LM, Scott SM, et al. Chorioamnionitis and early lung inflammation in infants in whom bronchopulmonary dysplasia develops. Pediatrics 1996;97:210-15.

25. Ogunyemi D, Murillo $\mathrm{M}$, Jackson $\mathrm{U}$, et al. The relationship between placental histopathology findings and perinatal outcome in preterm infants. J Matern Fetal Neonatal Med 2003:13:102-9.

26. Fawke J, Lum S, Kirkby J, et al. Lung function and respiratory symptoms at 11 years in children born extremely preterm. Am J Respir Crit Care Med 2010:182:237-45.

27. Filippone $\mathbf{M}$, Sartor M, Zacchello F, et al. Flow limitation in infants with bronchopulmonary dysplasia and respiratory function at school age. Lancet 2003:361:753-4.

28. Doyle LW, Chavasse R, Ford GW, et al. Changes in lung function between 8 and 14 years in children with birth weight of less than 1,501g. Pediatr Pulmonol 1999:27:185-90.

29. Sukstanskii AL, Conradi MS, Yablonskiy DA. ${ }^{3} \mathrm{He}$ lung morphometry technique: accuracy analysis and pulse sequence optimization. J Magn Reson 2010:207:234-41.

\title{
Differentiation of malignant pleural mesothelioma from other pleural diseases
}

In this study, pleural effusion samples from 101 patients with suspected or newly diagnosed malignant pleural mesothelioma (MPM) or metastatic adenocarcinoma (ADCA) were collected between 1998 and 2010. Of the 101 patients, 65 were diagnosed with MPM, 25 with ADCA and 15 with benign pleural effusion. Cancer cells isolated from pleural effusion samples were subjected to genome-wide gene expression analysis, done with the help of microarrays and real-time PCR.

The study found 74 genes coding for markers that were overexpressed in MPM and 9 genes that were overexpressed in ADCA. The highest expression in MPM cells was the gene COL3A1, coding for type III collagen. Immunohistochemistry demonstrated 100\% staining of MPM biopsy samples with antibodies specific for COL3A1 and no staining in ADCA.

Soluble markers such as CCL2 and galectin-3 were identified as useful markers for diagnosing MPM. CCL2 concentration was significantly higher in patients with MPM than in patients with ADCA or benign pleural effusion whereas galectin-3 was significantly lower in MPM compared with ADCA. CCL2 and COL3A1 can be used as positive markers, whereas galectin-3 can be used as a negative marker. Statistical analysis using receiver operating characteristic curve and sensitivity suggested that both these markers performed better than existing markers in differentiating MPM from other pleural diseases.

Although type III collagen, CCL2 and galectin-3 markers have been shown to be valuable diagnostic aids, a large multicentre study is required to validate these results and investigate other potential markers.

Gueugnon F, Leclercq S, Blanquart C, et al. Identification of novel markers for the diagnosis of malignant pleural mesothelioma. Am J Pathol 2011;178:1033-42.

\section{R Bhardwaj}

Correspondence to Dr R Bhardwaj, Foundation Year 1, St James University Hospital, Leeds, UK; rahulbhardwaj@doctors.org.uk

Published Online First 17 May 2011

Thorax 2012;67:61. doi:10.1136/thoraxjnl-2011-200355 